\title{
携帯型コロナ放電イオン化方式イオンモビリティー スペクトロメーターの化学剤検知性能
}

\author{
關岡 亮二 ${ }^{1,3}$, 高山 康男 ${ }^{1,3}$, 瀬戸 康雄 $^{\circledR 1}$, 浦崎友貴緒 ${ }^{2}$, 新 澤 仁 $^{2}$
}

\section{1 緒言}

化学剤（化学兵器用剤, chemical warfare agent）は, 即効性で, 微量で殺傷性, 無能力性を示し ${ }^{12)}$, 神経ガス,

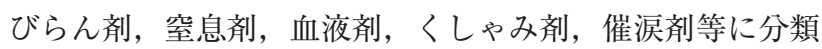
される ${ }^{3)} .1992$ 年に化学兵器の開発，生産，貯蔵及び使用 の禁止並びに廃棄に関する条約が国連総会で採択され4), 1995 年に我が国で化学兵器の禁止及び特定物質の規制等 に関する法律（化学兵器禁止法）が成立し，1997 年に化 学兵器禁止条約が発効した ${ }^{5)}$. 化学剂は従来は戦争遂行に 用いられたが, 1994 年の松本, 1995 年の東京地下鉄サリ ン事(件 ${ }^{6 / 7)}, 2001$ 年の米国航空機同時多発テロ以降の郵便 物炭癫菌事件が発生し，生物剂，化学剂等の大量殺傷型兵 器を用いたテロの脅威は顕在化している. 化学剂テロ事件 の危機管理対応として ${ }^{3)}$, 被害者救命, 初動捜査の必要上 一刻も早い原因物質の特定が要求される. また, テロ現場 における初動措置隊の個人防護的観点から, 現場検知が最 重要となる. 現在, 軍用仕様の化学剤検知資機材が市販化 されているが8)，実際にテロの現場で性能を発揮するか否 かは保証はない，著者らはこれまでに，実剂又は擬剤を用 いて市販の生物・化学剂検知資機材の性能を検証してき $た^{9) \sim 17)}$. 要求される現場化学剂検知器の性能として, 携 带性, 簡便性, 検知迅速性, 検出感度, 選択性, 耐久性等 が要求されるが8), 感度が足りない, 誤判定がある, 警報 応答が遅い, 警報後の復㷌が遅い等の性能上の問題点が指 摘される. 本論文では, 市販のイオンモビリティスペクト ロメーター（IMS）検知器 ${ }^{18}$ のひとつであり各国の防衛機 関や初動措置隊に採用されている LCD 3.2E について，化 学剂に対する検知性能を検証したので報告する。

\section{2 材料及び方法}

\section{$2 \cdot 1$ 装 置}

英国 Smiths Detection 製 ${ }^{19)} の$ lightweight chemical detector $\{\mathrm{LCD}$, version 3.2 Enhanced (3.2E) $\}$ は, 高さ

\footnotetext{
${ }^{1}$ 科学警察研究所：277-0882 千葉県柏市柏の葉 6-3-1

2 株式会社山田洋行：106-6040 東京都港区六本木 1-6-1

${ }^{3}$ 現在所属 警視庁：100-8929 東京都千代田区霞が関 2-1-1
}

約 $18 \mathrm{~cm}$, 幅約 $11.5 \mathrm{~cm}$, 厚さ約 $4.5 \mathrm{~cm}$, 本体重量約 $545 \mathrm{~g}$ (電池, シーブパック込み), 単三型 (AA タイプ) 乾電池（4 個, バッテリーカセットに挿入）駆動の携带型 化学剂検知器である (Fig. 1). 上面のレインキャップを 反時計回りにひ权り，ポインターを“OFF”のロック位置 からマーク部分に合わせると（電源オン），パネル上のす ベてのアイコンが瞬間に点灯して短い音が鳴る．続いてウ オームアップモード 仩面（top display）及び前面（front display）パネル黄色砂時計マーク（hourglass icon）点滅\} になり，自己診断で正常作動可能になれば（おおむね 1 分程度), 検知モード 䌷面パネル黄色チェックマーク (tick icon）点滅\}になり，レインキャップ開口部から外 部空気の連続的な吸引 $(1.5 \mathrm{~L} / \mathrm{min})$ が開始する。検知モ ードは 2 種類あり，化学剤を検知する場合は前面パネル の CW icon が点灯する。側面のコントロールボタンを押 し続ければ, CW icon が消灯し，代わって TIC icon が点 灯し，毒性工業化学物質（TIC）を検知する。本実験では, 化学剂検知モードを検討した。空気試料を吸引し，本体内 部のコロナ放電部分で吸引成分はイオン化を受け，IMS の原理で吸引成分由来イオンを分離，検出する．吸引ガス はレインキャップ開口部吸引口の反対側から排出される.

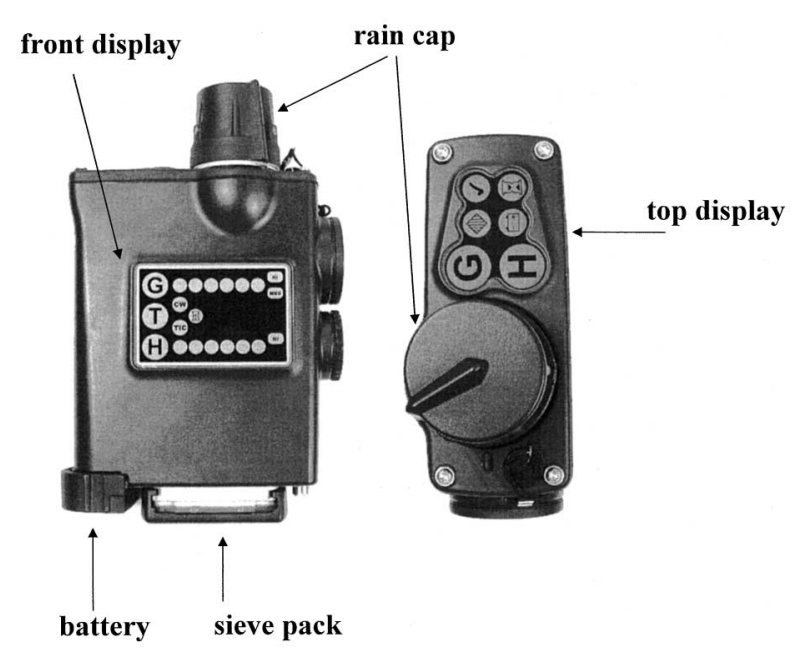

Fig. 1 The picture of LCD-3.2E 
化学剤として認識されると警報が表示され，LEDの点滅 と警告音が発せられる，パネル上で，化学剤の種別 \{上面 及び前面パネル赤色 $\mathrm{G} マ ー ク （ G$ icon）点滅: 神経ガス, 赤色 H マーク（H icon）点滅：びらん剂，血液剂，窒息 剂\}を表示する。併せて, 前面パネルに濃度レベル表示 （hazard level：6 個の円形バーグラフ）が表れる。警報表 示後, 残留化学剤の污染度が低下すれば, 検知モードに復 州する．LCD 3.2E は，本体底部にシーブパックを装着し, 吸引空気を浄化し，IMS セルに浄化空気を送る。装置の 異常, 環境異常 $\left(-30 \sim 40^{\circ} \mathrm{C}\right.$ 以外, 湿度 $8 \sim 100 \%$ 以外, 気圧 $750 \sim 1050 \mathrm{mb}$ 以外), シーブパックの劣化によって, ウォームアップモードから検知モードに移らなくなる.

\section{$2 \cdot 2$ 試 薬}

サリン（O-isopropyl methylphosphonofluoridate, GB), ソマン (O-pinacolyl methylphosphonofluoridate, GD), タブン (O-ethyl $N, N$-dimethyl phosphoramidocyanidate, GA), マスタードガス \{bis(2-chloroethyl)sulfide, HD 及びルイサイト 1 (2-chlorovinyldichloroarsine, L1) は, オランダ TNO Prins Maurits Laboratoryより輸入した. 6 品の純度は $98 \%$ 以上（TNO 保証）であった.クロルピ クリン（PS）は，三井化学製燻蒸剤（東京）を用いた. その他の試薬は, 市販の特級品, 又は残留農薬, ポリ塩化 ビフェニル（PCB）試験用有機溶媒を用いた。

\section{$2 \cdot 3$ ガスの調製}

既知濃度の化学剤 (GB, GD, GA, HD, L1, PS）の $n$-ヘキサン溶液 $5 \mu \mathrm{L}$ を GL サイエンス製 $500 \mathrm{~mL}$ 容セミ ニードルバルブ付き気体採取容器 $(500 \mathrm{~mL}$ ガス採取管） に取り, 密封してドライヤーで 1 分加熱し, 気化ガスを 調製した。

既知濃度の青酸カリウム水溶液（1 mL 以内）をシャー レに取り，10 L 容パイレックスガラス容器に入れ，青酸 に対してモル量以上の $10 \%$ 硫酸（水素イオンとして約 $2 \mathrm{M})$ 水溶液をシャーレに加え, 素早くふたをし, 密閉に して，青酸（AC）ガスを調製した。同様に，既知濃度の 青酸カリウム水溶液をシャーレに取り $10 \mathrm{~L}$ 容器に入れ, 青酸に対して 1.2 モル量以上の $0.2 \mathrm{M}$ クロラミン $\mathrm{T}$ 水溶液 を加え，素早くふたをして塩化シアン（CK）ガスを調製 した。

化学剂の擬剂及び有機溶剤はその $1 \mu \mathrm{L}$ を $500 \mathrm{~mL}$ ガス 採取管に取り, 密封してドライヤーで 1 分加熱し蒸発さ せ，気化ガスを調製した。希釈濃度ガスは，対象試薬の $n$-ヘキサン溶液 $5 \mu \mathrm{L}$ を $500 \mathrm{~mL}$ ガス採取管に取り, 密封 してドライヤーで 1 分加熱し蒸発させ, 気化ガスを調製 した。

\section{$2 \cdot 4$ 検知実験}

化学剤の検知実験は, LCD 3.2E 本体を検知モードで待 機させ，化学剂気化ガス入りの $500 \mathrm{~mL}$ ガス採取管の片方 の口を LCD 3.2E 本体の吸入口に近づけ，もう一方の口か らシリコンチューブで連結したガラス注射筒 $(100 \mathrm{~mL}$ 容 $)$ で連続的に押し出し (約 $500 \mathrm{~mL} / \mathrm{min}$ ), 気化ガスを LCD $3.2 \mathrm{E}$ 吸入口に噴射した。警報が表示されると，気化ガス の噴射を停止した．気化ガス噴射時間は最長 1.5 分とし た。

$\mathrm{AC}$ ガス, $\mathrm{CK}$ ガスの検知実験は, 気化ガス入り $10 \mathrm{~L}$ 容 器からガラス注射筒（100 mL 容）でガスを吸引して，素 早く LCD 3.2E 注入口に吸引ガスを約 $500 \mathrm{~mL} / \mathrm{min}$ で噴射 する操作を繰り返し，警報が表示されると，気化ガスの噴 射を停止した。気化ガス噴射時間は最長 1.5 分とした。

市販タバコ（MILD SEVEN ORIGINAL 10，内容表示： タール $10 \mathrm{mg}$ ，ニコチン $0.8 \mathrm{mg}$ ) に火をつけふかし，煙 を発生させ，LCD 3.2E 本体に吸引させた。また，夕バコ を吸い, 口から煙を吐き出し, LCD 3.2E 本体に突きつけ た. タバコ煙中の ACの定量は，ドイツ Draeger 製ガス検 知管「Hydrocyanic acid」を用いて行った。

\section{$2 \cdot 5$ 特定物質使用に関する注意}

化学剤は猛毒であり, 化学兵器禁止法 ${ }^{5)}$ に従い経済産業 大臣より認可を受け，スクラバー式ドラフトチャンバー内 で，防護マスク，服，手袋を装着して実験を行った。

\section{3 結果}

\section{$3 \cdot 1$ 化学剤に対する検知結果}

n-ヘキサンは，LCD 3.2E によっては陽性を示さなかっ たので，神経ガス，びらん剤，PS は $n$-ヘキサンに溶解さ せその希釈溶液を気化させ，検知に供した。化学剂の気化 ガスを LCD 3.2E に吸引させた場合の検知結果を Table 1 に示す、神経ガスである GB の気化ガスは， $0.2 \mathrm{mg} / \mathrm{m}^{3}$ の 濃度において 4 秒の吸引で警報率 $100 \%$ で“G”の警報が 表示され，hazard level は 4 であった。GB 濃度が低下す るにつれて警報率は低下し， $0.1 \mathrm{mg} / \mathrm{m}^{3}$ の濃度において警 報が表れなかった。GD 及び GAの気化ガスは，0.15 $\mathrm{mg} / \mathrm{m}^{3}, 0.3 \mathrm{mg} / \mathrm{m}^{3}$ の濃度において“G”の警報（hazard level：4）が警報率 100\% で表示された。GAの低濃度検 知の場合を除き, 警報を発した後, 数秒以内で解除された。 神経ガスの濃度が高くなるにつれて，警報が表れるまでの 時間は短くなり，表示 hazard level が上がる傾向が認めら れた。また，神経ガス濃度が高い場合は，警報後の復帰ま での時間は長くなった.

びらん剤である HD の気化ガスは， $12 \mathrm{mg} / \mathrm{m}^{3}$ の濃度に おいて 2 秒の吸引で“H” の警報が警報率 $100 \%$ で表示さ れ， hazard level は 4 であった. HD 濃度が低下するにつ 
Table 1 Detection of chemical warfare agents by LCD-3.2E

\begin{tabular}{|c|c|c|c|c|c|c|}
\hline \multirow{2}{*}{ Agent } & \multirow{2}{*}{$\begin{array}{c}\text { Concentration/ } \\
\mathrm{mg} \mathrm{m}^{-3}\end{array}$} & \multirow{2}{*}{ Alarm/trial } & \multirow{2}{*}{$\begin{array}{l}\text { Response } \\
\text { time/s }\end{array}$} & \multirow{2}{*}{$\begin{array}{l}\text { Recovery } \\
\text { time/s }\end{array}$} & \multicolumn{2}{|c|}{ Alarm } \\
\hline & & & & & Class & Hazard level \\
\hline \multirow[t]{6}{*}{ GB } & 0.1 & $0 / 4$ & & & & \\
\hline & 0.15 & $2 / 3$ & $4 \sim 5$ & $2 \sim 3$ & G & $3 \sim 4$ \\
\hline & 0.2 & $3 / 3$ & 4 & $3 \sim 4$ & G & 4 \\
\hline & 0.4 & $1 / 1$ & 5 & 3 & G & 4 \\
\hline & 1.0 & $3 / 3$ & $3 \sim 4$ & $3 \sim 4$ & G & 4 \\
\hline & 20 & $1 / 1$ & 2 & 25 & G & 6 \\
\hline \multirow[t]{7}{*}{ GD } & 0.05 & $0 / 3$ & & & & \\
\hline & 0.1 & $2 / 4$ & 20 & 80 & G & 4 \\
\hline & 0.15 & $3 / 3$ & $5 \sim 8$ & 4 & G & 4 \\
\hline & 0.2 & $4 / 4$ & $5 \sim 14$ & 3 & G & 4 \\
\hline & 0.4 & $1 / 1$ & 5 & 3 & G & 4 \\
\hline & 1.0 & $1 / 1$ & 4 & 3 & G & 4 \\
\hline & 20 & $1 / 1$ & 1 & 90 & G & 6 \\
\hline \multirow[t]{7}{*}{ GA } & 0.2 & $0 / 3$ & & & & \\
\hline & 0.25 & $2 / 3$ & $10 \sim 30$ & 3 & G & $3 \sim 4$ \\
\hline & 0.3 & $3 / 3$ & $4 \sim 30$ & 3 & G & 4 \\
\hline & 0.4 & $3 / 3$ & $3 \sim 16$ & 3 & G & 4 \\
\hline & 0.6 & $3 / 3$ & $6 \sim 20$ & 3 & G & 4 \\
\hline & 1.0 & $1 / 1$ & 1 & 3 & G & 4 \\
\hline & 20 & $1 / 1$ & 1 & 20 & G & 6 \\
\hline \multirow[t]{5}{*}{ HD } & 6.0 & $0 / 3$ & & & & \\
\hline & 9.0 & $2 / 3$ & $2 \sim 5$ & 3 & $\mathrm{H}$ & 3 \\
\hline & 12 & $3 / 3$ & 2 & 3 & $\mathrm{H}$ & 4 \\
\hline & 24 & $3 / 3$ & 2 & $3 \sim 4$ & $\mathrm{H}$ & 4 \\
\hline & 120 & $1 / 1$ & 3 & 8 & $\mathrm{H}$ & 6 \\
\hline \multirow[t]{8}{*}{ L1 } & 1.9 & $0 / 3$ & & & & \\
\hline & 2.85 & $1 / 3$ & 5 & 2 & $\mathrm{H}$ & 3 \\
\hline & 3.8 & $2 / 4$ & 5 & 2 & $\mathrm{H}$ & 3 \\
\hline & 5.7 & $3 / 3$ & 4 & 2 & $\mathrm{H}$ & 3 \\
\hline & 7.6 & $3 / 3$ & $2 \sim 3$ & $2 \sim 3$ & $\mathrm{H}$ & $3 \sim 4$ \\
\hline & 19 & $1 / 1$ & 3 & 3 & $\mathrm{H}$ & 6 \\
\hline & 95 & $1 / 1$ & 2 & 16 & $\mathrm{H}$ & 4 \\
\hline & 190 & $1 / 1$ & 2 & 24 & $\mathrm{H}$ & 6 \\
\hline \multirow[t]{6}{*}{$\mathrm{AC}$} & 10 & $0 / 3$ & & & & \\
\hline & 12.5 & $1 / 4$ & 5 & 3 & $\mathrm{H}$ & 6 \\
\hline & 15 & $3 / 3$ & $4 \sim 5$ & 3 & $\mathrm{H}$ & 6 \\
\hline & 20 & $3 / 3$ & 5 & 3 & $\mathrm{H}$ & 6 \\
\hline & 50 & $3 / 3$ & $3 \sim 4$ & 3 & $\mathrm{H}$ & 6 \\
\hline & 100 & $3 / 3$ & $3 \sim 4$ & $3 \sim 4$ & $\mathrm{H}$ & 6 \\
\hline \multirow[t]{5}{*}{$\mathrm{CK}^{\mathrm{a})}$} & 400 & $0 / 2$ & & & & \\
\hline & 500 & $1 / 2$ & 14 & 4 & $\mathrm{H}$ & 6 \\
\hline & 600 & $0 / 1$ & & & & \\
\hline & 1000 & $0 / 3$ & & & & \\
\hline & 2000 & $3 / 3$ & $2 \sim 6$ & 4 & $\mathrm{H}$ & $5 \sim 6$ \\
\hline \multirow[t]{5}{*}{$\mathrm{CK}^{\mathrm{b})}$} & 300 & $0 / 5$ & & & & \\
\hline & 400 & $1 / 5$ & 12 & 4 & $\mathrm{H}$ & 6 \\
\hline & 500 & $3 / 3$ & $5 \sim 6$ & 4 & $\mathrm{H}$ & 6 \\
\hline & 1000 & $3 / 3$ & $7 \sim 10$ & 4 & $\mathrm{H}$ & 6 \\
\hline & 2000 & $3 / 3$ & $2 \sim 4$ & 4 & $\mathrm{H}$ & 6 \\
\hline \multirow[t]{6}{*}{ PS } & 8.0 & $0 / 2$ & & & & \\
\hline & 12.8 & $2 / 2$ & $6 \sim 7$ & 4 & $\mathrm{H}$ & 6 \\
\hline & 16 & $2 / 2$ & $3 \sim 4$ & $4 \sim 5$ & $\mathrm{H}$ & 6 \\
\hline & 32 & $2 / 2$ & $2 \sim 3$ & $4 \sim 5$ & $\mathrm{H}$ & 6 \\
\hline & 320 & $2 / 2$ & $1 \sim 2$ & 4 & $\mathrm{H}$ & 6 \\
\hline & 3200 & $3 / 3$ & 2 & $5 \sim 6$ & $\mathrm{H}$ & 6 \\
\hline
\end{tabular}

a) The experiments were performed using the detector equipped with a Sieve Pack which had been used for more than one month. b) The experiments were performed using the detector equipped with newly replaced Sieve Pack. 
Table 2 Detection of chemical warfare agent simulant vapors by LDC-3.2E

\begin{tabular}{|c|c|c|c|c|c|c|}
\hline \multirow{2}{*}{ Agent } & \multirow{2}{*}{$\begin{array}{c}\text { Concentration/ } \\
\mathrm{mg} \mathrm{m}^{-3}\end{array}$} & \multirow{2}{*}{ Alarm/trial } & \multirow{2}{*}{$\begin{array}{l}\text { Response } \\
\text { time/s }\end{array}$} & \multirow{2}{*}{$\begin{array}{l}\text { Recovery } \\
\text { time/s }\end{array}$} & \multicolumn{2}{|c|}{ Alarm } \\
\hline & & & & & Class & Hazard level \\
\hline Dimethylmethylphosphonate & 2320 & $0 / 4$ & & & & \\
\hline \multirow[t]{3}{*}{ Trimethylphosphate } & 122 & $0 / 2$ & & & & \\
\hline & 244 & $2 / 2$ & 3 & 4 & G & 6 \\
\hline & 2440 & $3 / 3$ & $4 \sim 6$ & 4 & G & 6 \\
\hline \multirow[t]{3}{*}{ Triethylphosphate } & 86 & $0 / 2$ & & & & \\
\hline & 107 & $2 / 2$ & $4 \sim 5$ & 4 & G & 6 \\
\hline & 2140 & $2 / 2$ & $20 \sim 24$ & $420 \sim 780$ & G & 6 \\
\hline 2-chloroethylethylsulfide & 2140 & $0 / 4$ & & & & \\
\hline \multirow[t]{2}{*}{ 1,4-thioxane } & 1670 & $0 / 2$ & & & & \\
\hline & 2230 & $3 / 3$ & $24 \sim 32$ & 3 & G & 4 \\
\hline \multirow[t]{3}{*}{ 2-mercaptoethanol } & 222 & $0 / 2$ & & & & \\
\hline & 1110 & $2 / 2$ & $3 \sim 4$ & 4 & $\mathrm{H}$ & 4 \\
\hline & 2220 & $3 / 3$ & $2 \sim 3$ & $4 \sim 5$ & $\mathrm{H}$ & 4 \\
\hline
\end{tabular}

れて警報率は低下し, $6 \mathrm{mg} / \mathrm{m}^{3}$ の濃度において警報が表 れなかった．L1 の気化ガスは, $5.7 \mathrm{mg} / \mathrm{m}^{3}$ の濃度におい て 4 秒の吸引で “H” の警報が警報率 100\% で表示され， hazard level は3〜4であった。 L1 濃度が低下するにつれ て警報率は低下し， $1.9 \mathrm{mg} / \mathrm{m}^{3}$ の濃度において警報が表れ なかった、警報を発した後, 数秒以内で解除された。びら ん剤の濃度が高くなるにつれて, 表示 hazard level が上が り，警報後の復帰までの時間は長くなる傾向が認められ た。

血液剤である $\mathrm{AC}$ ガスは, $15 \mathrm{mg} / \mathrm{m}^{3}$ の濃度において 4 ～5 秒の吸引で “H” の警報が警報率 100\% で表示され， hazard level は 6 であった。 AC 濃度が低下するにつれて 警報率は低下し, $10 \mathrm{mg} / \mathrm{m}^{3}$ の濃度において警報が表れな かった．CK ガスは，シーブパックを取り替えたばかりの 試験に执いては, $500 \mathrm{mg} / \mathrm{m}^{3}$ の濃度に扔いて $5 \sim 6$ 秒の吸 引で“H”の警報が警報率 $100 \%$ で表示され，hazard level は 6 であった. CK 濃度が低下するにつれて警報率は 低下し, $300 \mathrm{mg} / \mathrm{m}^{3}$ の濃度に扔いては警報が表れなかっ た。しかし，シーブパックを一か月以上使用した状態での 試験においては, “H”の警報を示す CK 濃度は 2000 $\mathrm{mg} / \mathrm{m}^{3}$ であった。なお，他の剤に関する検知実験におい ては，シーブパックの使用期間に依存した陽性率の変化は 特に認められなかった。

窒息剤である PS の気化ガスは, $12.8 \mathrm{mg} / \mathrm{m}^{3}$ の濃度に 拈いて 6 7 秒の吸引で “H” の警報が警報率 $100 \%$ で表 示され, hazard level は 6 であった. $8 \mathrm{mg} / \mathrm{m}^{3}$ の濃度にお いて警報が表れなかった，警報を発した後，数秒以内で解 除された。

\section{$3 \cdot 2$ 化学剤擬剤の検知実験}

擬剂の気化ガスを LCD 3.2E に吸引させた場合の検知結 果を Table 2 に示す．神経ガスの擬剤 dimethylmethylphos- phonate は警報を示さなかったが, trimethylphosphate （TMPO）及び triethylphosphate（TEPO）は高濃度の場 合 “G” の警報が表示された。TMPO は数秒の吸引で警報 が表れ，数秒以内で警報が解除されたが，TEPO は数十秒 の吸引で警報が表れ，警報が解除されるまでに数〜十数分 を要した，両者ともに低濃度で警報は表れず，検知感度は $100 \mathrm{mg} / \mathrm{m}^{3}$ 前後であった．HD の擬剂 2-chloroethylethylsulfide は警報を示さなかったが，HDの分解副産物である 1,4-thioxane は高濃度では数十秒の吸引で “G” の警報が 表示され，3秒後に警報は解除された。硫黄化合物 2-mercaptoethanol は, 高濃度で数秒以内の吸引で “H”の警報 が表示され，数秒後に警報は解除された。両者共に低濃度 では警報は表れず，検知感度は $1000 \mathrm{mg} / \mathrm{m}^{3}$ 前後であっ た.

\section{$3 \cdot 3$ 有機溶媒の検知結果}

有機溶媒の気化ガスを LCD 3.2E に吸引させた場合の検 知結果を Table 3 に示す。検討した有機溶媒はお打むね 警報を示さなかったが，例外として $n$-プロピルアルコー ル, ジエチルアミン, トリエチルアミン $N, N$-ジメチル ホルムアミドは高濃度で “G”の警報が表示され，ジエチ ルエーテル，酢酸は高濃度で“H”の警報が表示された。 ホルムアルデヒドは，試験ごとに“G” 及び “H” の警報 が表示された。偽陽性を示した有機溶媒は，お抢むね低濃 度 $\left(500 \mathrm{mg} / \mathrm{m}^{3}\right.$ 以下）で警報は表れなかったが，ホルム アルデヒド及びトリエチルアミンの検知感度はおお打むね $100 \mathrm{mg} / \mathrm{m}^{3}$ であり, ジエチルアミン及び $N, N$-ジメチルホ ルムアミドは扔扮むね $10 \mathrm{mg} / \mathrm{m}^{3}$ であった。残留農薬， PCB 試験用の高純度のアセトンは, 高濃度でも陰性であ ったが, 特級試薬は高濃度 $\left(13000 \mathrm{mg} / \mathrm{m}^{3}\right.$ 前後) におい て“H”の警報が表示された。 
Table 3 Detection of organic solvents by LCD-3.2E

\begin{tabular}{|c|c|c|c|c|c|c|}
\hline \multirow{2}{*}{ Agent } & \multirow{2}{*}{$\begin{array}{c}\text { Concentration/ } \\
\mathrm{mg} \mathrm{m}^{-3}\end{array}$} & \multirow{2}{*}{ Alarm/trial } & \multirow{2}{*}{$\begin{array}{l}\text { Response } \\
\text { time/s }\end{array}$} & \multirow{2}{*}{$\begin{array}{l}\text { Recovery } \\
\text { time } / \mathrm{s}\end{array}$} & \multicolumn{2}{|c|}{ Alarm } \\
\hline & & & & & Class & Hazard level \\
\hline$n$-pentane & 1260 & $0 / 3$ & & & & \\
\hline \multirow{2}{*}{$n$-hexane $e^{\text {a) }}$} & 1320 & $0 / 3$ & & & & \\
\hline & 6600 & $0 / 3$ & & & & \\
\hline Cyclohexane & 1550 & $0 / 3$ & & & & \\
\hline 2-methylbutane & 1730 & $0 / 3$ & & & & \\
\hline$n$-heptane & 1360 & $0 / 3$ & & & & \\
\hline Toluene & 1730 & $0 / 3$ & & & & \\
\hline Benzene & 1750 & $0 / 3$ & & & & \\
\hline Xylene & 1760 & $0 / 3$ & & & & \\
\hline \multirow[t]{2}{*}{ Methanol $^{\text {a) }}$} & 1580 & $0 / 3$ & & & & \\
\hline & 7900 & $0 / 3$ & & & & \\
\hline Ethanol & 1570 & $0 / 3$ & & & & \\
\hline \multirow[t]{2}{*}{$n$-propyl alcohol ${ }^{\text {a) }}$} & 1440 & $0 / 2$ & & & & \\
\hline & 1600 & $4 / 4$ & $3 \sim 5$ & 4 & G & 4 \\
\hline 2-propylalcohol ${ }^{\text {a) }}$ & 1570 & $0 / 3$ & & & & \\
\hline$n$-butanol & 1620 & $0 / 3$ & & & & \\
\hline Isobutylalcohol & 1620 & $0 / 3$ & & & & \\
\hline \multirow[t]{2}{*}{ Diethylether ${ }^{a)}$} & 710 & $0 / 2$ & & & & \\
\hline & 1420 & $3 / 3$ & $5 \sim 7$ & 3 & $\mathrm{H}$ & 4 \\
\hline 1,4-dioxane & 2060 & $0 / 3$ & & & & \\
\hline Hetrahydrofuran & 1780 & $0 / 3$ & & & & \\
\hline \multirow[t]{2}{*}{ Acetone $^{\text {a) }}$} & 1580 & $0 / 3$ & & & & \\
\hline & 15800 & $0 / 2$ & & & & \\
\hline \multirow[t]{5}{*}{ Acetone } & 1580 & $0 / 3$ & & & & \\
\hline & 9450 & $0 / 3$ & & & & \\
\hline & 11100 & $1 / 2$ & 7 & 3 & $\mathrm{H}$ & 3 \\
\hline & 12600 & $2 / 2$ & $6 \sim 10$ & 4 & $\mathrm{H}$ & 4 \\
\hline & 15800 & $2 / 2$ & $6 \sim 7$ & 4 & $\mathrm{H}$ & 4 \\
\hline \multirow[t]{3}{*}{ Formaldehyde $^{\text {b) }}$} & 35 & $0 / 2$ & & & & \\
\hline & 175 & $2 / 2$ & $7 \sim 10$ & $3 \sim 4$ & G & 2 \\
\hline & 350 & $3 / 3$ & 3 & $3 \sim 4$ & $\mathrm{G}, \mathrm{H}$ & $4 \sim 6$ \\
\hline Acetaldehyde $^{c)}$ & & $0 / 3$ & J & & & \\
\hline Ethylacetate $^{\text {a) }}$ & 1800 & $0 / 3$ & & & & \\
\hline Dichloromethane $^{\text {a) }}$ & 2660 & $0 / 3$ & & & & \\
\hline Chloroform ${ }^{\text {a) }}$ & 2960 & $0 / 3$ & & & & \\
\hline Acetonitrile & 1560 & $0 / 3$ & & & & \\
\hline \multirow[t]{3}{*}{ Acetic acid ${ }^{\text {b) }}$} & 1100 & $0 / 2$ & & & & \\
\hline & 1580 & $2 / 2$ & $5 \sim 8$ & 4 & $\mathrm{H}$ & 6 \\
\hline & 2100 & $3 / 3$ & $3 \sim 4$ & 4 & $\mathrm{H}$ & 6 \\
\hline $\mathrm{HCl}^{\mathrm{b})}$ & 720 & $0 / 3$ & & & & \\
\hline Ammonia ${ }^{\mathrm{b})}$ & 500 & $0 / 3$ & & & & \\
\hline Diethylamine $\mathrm{e}^{\mathrm{d})}$ & 7 & $0 / 2$ & & & & \\
\hline & 14 & $1 / 2$ & 9 & 4 & G & 3 \\
\hline & 28 & $2 / 2$ & $6 \sim 7$ & 4 & G & 4 \\
\hline & 70 & $2 / 2$ & $3 \sim 4$ & 4 & G & 4 \\
\hline & 1400 & $3 / 3$ & 2 & $4 \sim 5$ & G & $5 \sim 6$ \\
\hline Triethylamine $^{\mathrm{d})}$ & 73 & $0 / 2$ & & & & \\
\hline & 145 & $2 / 2$ & $6 \sim 7$ & 4 & G & 3 \\
\hline & 218 & $2 / 2$ & $5 \sim 6$ & 4 & G & 4 \\
\hline & 363 & $2 / 2$ & $5 \sim 6$ & 4 & G & $3 \sim 4$ \\
\hline & 725 & $2 / 2$ & $7 \sim 8$ & 4 & G & $4 \sim 5$ \\
\hline & 1450 & $3 / 3$ & $2 \sim 3$ & $4 \sim 5$ & G & $5 \sim 6$ \\
\hline$N, N$-dimethylformamide ${ }^{\mathrm{d})}$ & 1.9 & $0 / 2$ & & & & \\
\hline & 3.8 & $2 / 2$ & $5 \sim 8$ & 4 & G & $4 \sim 5$ \\
\hline & 9.4 & $2 / 2$ & 4 & 4 & G & 5 \\
\hline & 19 & $2 / 2$ & $2 \sim 3$ & 8 & G & 4 \\
\hline & 95 & $2 / 2$ & $3 \sim 4$ & $12 \sim 16$ & G & 6 \\
\hline & 1890 & $3 / 3$ & 2 & $12 \sim 36$ & G & 6 \\
\hline Pyridine & 1960 & $0 / 3$ & & & & \\
\hline Aniline & 2040 & $0 / 3$ & & & & \\
\hline$N, N$-diethylaniline & 1860 & $0 / 3$ & & & & \\
\hline
\end{tabular}

a) Reagent grade solevents for analysis of residual agricultural chemicals and polychlorinated biphenyls were used. b) These reagents are dissolved in water. For the experiments using the low concentrations of solvents the original reagent solution were dissolved with distilled water and the detection experiments were examined. c) Vapor of acetaldehyde liquid was examined for the detection experiment. d) For the experiments using the low concentrations of the solvents the reagent were dissolved with methanol and examined for the detection experiment. 


\section{$3 \cdot 4$ タバコ煙の検知実験}

タバコ煙（副流煙）を LCD 3.2Eに吸引させた場合，2 〜3 秒で “G”の警報が表示され，hazard level は 4 であ り，警報を発した後，4秒で解除された。 タバコ煙（吐出 煙）をLCD 3.2E に吹き付けた場合，警報率 $2 / 3$ で 4 秒後 “G”及び “H”の警報が，また警報率 $1 / 3$ で 4 秒後 “ $G$ ” の警報がそして 20 秒後“H”の警報が表示された。 hazard level は 4 であり，警報を発した後，4秒で警報が解除 された。ガス検知管を用いて夕バコ煙中の $\mathrm{AC}$ 濃度を測定 したところ，副流煙は約 5 ppm，吐出煙は $1 〜 2 \mathrm{ppm}$ で あった。

\section{4 考察}

IMS は，化学剂検知器として最もはん用的に用いられ ている資機材である ${ }^{18)}$. IMS 検知の原理は，大気を吸引し て大気圧下で $\beta$ 線源等によりイオン化し特徵的な複数の 複合イオンを形成し，電子シャッター部で瞬間的にドリフ 卜領域（長さ数 $\mathrm{cm}$ ）に送り，電荷がかかったドリフト領 域（おおむね $200 \mathrm{~V} / \mathrm{cm}$ ）をイオンの大きさに応じたイオ ン移動度 (ion mobility, 数 msec) で移動しファラデーイ オンプレート到着までの時間，イオン強度を測定して化学

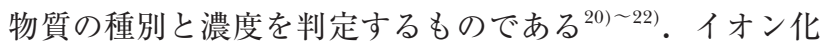
を受けやすい神経ガス，ニトロ系爆発物の検出感度は高 く，連続即時検知が可能である，装置は小型化が可能であ り，携帯でしかも衝撃にある程度耐えられ，化学兵器の中 では最も毒性の高い神経ガスに対して高感度であり理想的 な化学剂検知器といえる ${ }^{23)}$. 著者らは, 欧州で広く採用さ れている Environics OY 製のアスピレーション式 IMS 装置 に関して実剂を用いた性能評価を行っている ${ }^{1013)}$. 最近は, 放射線源の使用規制を避けて非放射線方式の装置が開発・ 製造されている ${ }^{24)}$. LCD 3.2E はコロナ放電をイオン化に 採用し，正負イオンを各々検知する 2 種の IMS セルを有 し，主に正極性のセルで神経ガスを，負極性のセルでびら ん剤，窒息剤，血液剤を測定する。シーブパックで浄化し た空気を IMS セルに送っているが，アンモニアガスが微 量含まれ，ドーパント分子として化学剤識別能が向上して いる。

本論文では，表面弾性波（SAW）型検知器 $\mathrm{JCAD}^{16)}$ や IMS 型検知器 ChemPro100 の性能評価 ${ }^{13)}$ で行った化学剂 ガスの調製方法である，化学剤の $n$-ヘキサン溶液の 500 $\mathrm{mL}$ ガス採取管内での気化操作を用いた。 $n$-ヘキサンは, LCD 3.2E に対しては反応を示さなかったので（Table 3), $n$-ヘキサンを希釈用溶媒に用いた。 $n$-ヘキサンに溶けない 試薬は，水又はメタノールを希釈用溶媒とした。化学剂気 化ガスを LCD 3.2E の吸引口に噴射する実験評価系を採用 しているので，一定濃度の化学剂含有ガスが検知器に吸引 されない。また，LCD 3.2E の吸引速度は $1.5 \mathrm{~L} / \mathrm{min}$ であ
るのに対して，化学剂ガス噴射速度は $0.5 \mathrm{~L} / \mathrm{min}$ と低い。 更に，噴射するガス中化学剤濃度は徐々に低下し，実験で 試みたガス中化学剤の実際の濃度は設定值よりは低いとい う限界がある。しかし，検知結果は再現性の高いものであ ったので（Table 1，2），本実験結果は概略的な検知性能 と見なすことができる。

化学剂の現場検知器には, 検知感度, 応答性, 正確性, 操作性，警報後復帰性が要求される ${ }^{25) 26)}$. 応答性に関して は, 吸着型検知器である $\mathrm{SAW}$ 検知器の $\mathrm{JCAD}^{13)}$ や他の IMS である M90 や ChemPro100 は検知器の材質の表面 （流路等）への吸着による警報後の復帰時間の長さが問題 であった。 LCD 3.2E は吸引大気の一部をシーブパックで 浄化し，浄化空気を検知部に送る機構であり，おおむね警 報後の復帰時間は短いという長所が認められた。

LCD 3.2E の検知感度に関しては，化学剤の吸入毒性值 である 1 分間吸入半数致死濃度 ${ }^{12)}$ を指標にして，得られ た検知限界值を評価できる。GB，GD，GA，HD，L1， $\mathrm{AC}, \mathrm{CK}$ 並びに PS の值は $70 \sim 100 \mathrm{mg} / \mathrm{m}^{3}, \quad 70 \sim 100$ $\mathrm{mg} / \mathrm{m}^{3}, \quad 200 \sim 400 \mathrm{mg} / \mathrm{m}^{3}, \quad 1500 \mathrm{mg} / \mathrm{m}^{3}, \quad 1200 \sim 1500$ $\mathrm{mg} / \mathrm{m}^{3}, \quad 2000 \sim 4500 \mathrm{mg} / \mathrm{m}^{3}, \quad 11000 \mathrm{mg} / \mathrm{m}^{3}, 2000$ $\mathrm{mg} / \mathrm{m}^{3}$ であり, その $1 / 100$ の濃度で検知することが求め られる3(25)26). Table 1 に示されるように, 神経ガスの GB, GD，GA，びらん剂の HD，L1 はおおむね上記の検知感 度要求を満たしていた。特に，血液剤の $\mathrm{AC}$ の検出感度は $15 \mathrm{mg} / \mathrm{m}^{3}$ であり, アスピレーション式 IMS 検知器が $\mathrm{AC}$ に対して検知性を示さない点と比較して ${ }^{10) 16}$ 検知感度は良 好である。しかし，血液剤の CK の検知感度は低く，上記 の検知感度要求を満たさなかった。 IMS 検知器に特有の, 低分子化合物に対する IMS 識別の困難さ，イオン化の低 さが原因と思われる。

LCD 3.2E の検知の正確度に関しては，一般的なイオン モビリティースペクトルのピーク分解能の低さから判断し て偽陽性反応が起こることが予想される．実験の結果，他 の IMS 検知器 ${ }^{10) 16)}$ の偽陽性反応のパターンとは異なるが, リン酸化合物やチオエーテル化合物が警報を示した。同様 に高濃度の有機溶剤に関しては，検討した化合物の中の約 20\%に対して偽陽性を示した。特に，偽陽性を示す化合 物の中では, $100 \mathrm{mg} / \mathrm{m}^{3}$ 程度で “G”警報を示すものが認 められた。しかし， $100 \mathrm{mg} / \mathrm{m}^{3}$ 程度で “ $\mathrm{H}$ ”警報を示す 化合物はなかった。アセトンのように，溶媒に含有される 不純物が偽陽性を示す場合もあり，未知物質に対する応答 性には注意を要する。

タバコの煙に対しては，吐出煙では“G”警報が，副流 煙では“G”及び “H”警報が表れた。タバコ煙は一酸化 炭素，AC，ニコチン等のアミン，芳香族炭化水素等の混 合物であり，煙中の測定 $\mathrm{AC}$ 濃度からは“H”警報を説明 できず，また LCD 3.2E がどの成分（又は複合として）を 
検知したかは現時点では不明である。テロ現場において は，有機溶剤の蒸気やタバコ煙は高濃度存在することも十 分予想されるものであり，偽陽性反応に十分注意を要す る.

現場検知器の多くは充電式バッテリーを採用しており, バッテリー不具合等問題があるが, LCD $3.2 \mathrm{E}$ は単三電池 駆動であり信頼性が高い. 操作はレインキャップや側面ボ タンを押すだけである，消耗品として，浄化空気を IMS セルに送るシーブパックが必要である. 使用時間とともに CKの検知感度が低下した（Table 1) が，これはシーブ パックの劣化が原因と思われる．頻繁に交換することが望 ましい.

LCD 3.2E は，神経ガスに対して“G”と表示し，びら

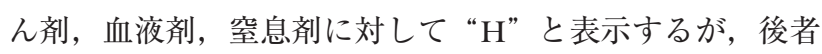
の識別は不可能である. 3 種類以上の識別を示す他の IMS 検知器の M90, ChemPro100, SAW 検知器の JCAD と比 較して識別種類は 2 個であり劣るものである. IMS 検知 器の識別能, 検知感度, 要求される検知感度を考慮してメ ーカーは開発したものと推察されるが, ガス性の血液剤, 窒息剤と, 揮発性のびらん剂を識別する検知プログラムを 開発することが望ましい。

LCD 3.2E の検知感度, 応答性, 正確度, 操作性, 警報 後復帰性の検証結果をかんがみれば，ホットゾーン等の危 険地域での初動の化学剂現場検知に有効であると結論され る.

\section{文献}

1) C. E. Stewart, J. B. Sullivan, Jr.: “Hazardous Materials Toxicology - Clinical Principles of Environmental Health", Edited by J. B. Sullivan, Jr., G. R. Krieger, p. 986 (1992), (Williams \& Wilkins, Baltimore).

2) S. M. Somani (ed.): "Chemical warfare agents", (1992), (Academic Press, San Diego).

3) 生物化学テロ災害対処研究会: “必携生物化学テ ロ対処ハンドブック”, (2003), (診断と治療社).

4) Organization for the Prohibition of Chemical Weapons: Chemical weapon convention. < http://www.opcw. org/>, 29 July, 2005.

5) 経済産業省：化学兵器禁止法の概要, < http://www. meti.go.jp/polycy/chemical_management/cwc/ 200kokunai/202horitu_gaiyo.htm >, 9 April, 2003.

6) 警察庁: 警察白書, 平成 7 年, 8 年.

7) Y. Seto, N. Tsunoda, M. Kataoka, K. Tsuge, T. Nagano: "Natural and selected Synthetic ToxinsBiological Implications", Edited by A. T. Tu, W. Gaffield, p. 318 (2000), (American Chemical Society, Washington, DC.).

8) J. P. Fittch, E. Raber, D. R. Imbro: Science, 302, 1350 (2003).

9) 糸井輝雄, 片岡美江子, 瀬戸康雄, 川原一芳, 飯 島潤一: 鑑識科学, 9, 9 (2004).

10) 瀬戸康雄, 井浦一光, 系井輝雄, 柘浩一郎, 片岡 美江子: 鑑識科学, 9, 39 (2004).

11) K. Iura, K. Tsuge, Y. Seto, A. Sato: Jpn. J. Forensic Toxicol., 22, 13 (2004).

12) Y. Fujinami. M. Kataoka, K. Matsushita, H. Sekiguchi, T. Itoi, K. Tsuge, Y. Seto: J. Health Sci., 50, 126 (2004).

13) 松下浩二, 関口裕之, 瀬戸康雄: 分析化学 (Bunseki Kagaku), 54, 83 (2005).

14) K. Tsuge, I. Ohsawa, K. Matsushita, H. Sekiguchi, Y. Seto, A. Sato: Jpn. J. Forensic Toxicol., 23, 18 (2005).

15) Y. Seto, M. Kanamori-Kataoka, K. Tsuge, I. Ohsawa, K. Matsushita, H. Sekiguchi, T. Itoi, K. Iura, Y. Sano, S. Yamashiro: Sens. Actuat. B, 108, 193 (2005).

16) 丸子 恒, 関口 浩, 瀬戸康雄, 佐藤晃詳: 分析化 学 (Bunseki Kagaku), 55, 191 (2006).

17) H. Sekiguchi, K. Matsushita, S. Yamashiro, Y. Sano, Y. Seto, T. Okuda, A. Sato: Forensic Toxicol., 24, 17 (2006).

18) G. A. Iceman, J. A. Stone: Anal. Chem., 76, 390A (2004).

19) Smiths Detection: LCD - Lightweight chemical detector, < http://trace.smithdetection.com/products/ Default.asp? Product $=19 \&$ section $=$ Facilities $>$, September 6, 2006.

20) F. W. Karasek: Anal. Chem., 46, 710A (1974).

21) R. H. St. Louis, H. H. Hill, Jr.: Crit. Rev. Anal. Chem., 21, 321 (1990).

22) H. H. Hill, Jr., W. F. Siems, R. H. St. Louis: Anal. Chem., 62, 1201A (1990).

23) R. Fanney (ed.): “Jane's Chem-Bio Handbook", 2nd ed., Ch. 8.1, (Jane's Information Group, Surrey), (2003).

24) K. Cottingham: Anal. Chem., 75, 435A (2003).

25) 瀬戸康雄: 薬学雑誌, 126, 1279 (2006).

26) 瀬戸康雄：分析化学 (Bunseki Kagaku), 55, 891 (2006). 


\title{
Detection Performance of Portable Colona Discharge Ionization Type Ion Mobility Spectrometer for Chemical Warfare Agents
}

\author{
Ryoji Sekioka $^{1}$, Yasuo Takayama ${ }^{1}$, Yasuo Seto $^{1}$, Yukio Urasaki $^{2}$ and Hitoshi Shinzawa ${ }^{2}$ \\ ${ }^{1}$ National Research Institute of Police Science, 6-3-1, Kashiwanoha, Kashiwa-shi, Chiba $277-0882$ \\ ${ }^{2}$ Yamada Corporation Co., LTD., Izumi Garden Tower, 1-6-1, Roppongi, Minato-ku, Tokyo 106-6040
}

(Received 5 October 2006, Accepted 25 November 2006)

The detection performance of a portable corona discharge ionization-type ion mobility spectrometer (LCD 3.2E, Smiths Detection) was investigated using nerve gases, blister agents, blood agents and related compounds. The vapors of sarin, soman and tabun were recognized as "G" after about several seconds of sampling; the detection limits were around $0.2 \mathrm{mg} / \mathrm{m}^{3}$. The vapors of mustard gas, lewisite 1 , hydrogen cyanide and chloropicrin were recognized as "H" after several seconds of sampling, and the detection limits were around $10 \mathrm{mg} / \mathrm{m}^{3}$. The vapors of cyanogen chloride were also recognized as "H", but the detection limit was around 500 $\mathrm{mg} / \mathrm{m}^{3}$. The vapors of trimethylphosphate, triethylphosphate, $n$-propanol, diethylamine, triethylamine, formaldehyde, and $N, N$-dimethylformamide were recognized as " $G$ ", and the vapors of 1,4-thioxane, 2-mercaptoethanol, diethylether and acetic acid were recognized as "H".

Keywords : chemical warfare agents; on-site detector; detection performance ; ion mobility spectrometer. 